振動流中で洏励振動している円柱と流れの相互作用について

Non-Linear Vortex-Excited Vibration of a Cylinder in Planar 0scillatory Flow

$$
\begin{aligned}
& \text { 防衛大学校土木工学教室 林 建 二 郎 Kenjirou Hayashi } \\
& \text { 防衛大学校土木工学教室 荻 原 洋 聡 Yousou Ogihara } \\
& \text { 防衛大学校土木工学教室 藤 間 功 司 Kouji Fujima } \\
& \text { 防衛大学校土木工学教室 重 村 利 幸 Toshiyuki Sigenura }
\end{aligned}
$$

This paper describes an experimental investigation into the non-linear vortex-excited vibration of a cylinder in planar oscillatory flow with emphasis being placed on the amplification of the forces acting on a cylinder caused by the fluid-structure interaction. The experiments were carried out using a water tank which has an internal dimension of $1.0 \mathrm{~m}$ long and $0.5 \mathrm{~m}$ deep by 0.5 m uide, and is oscillated in true harmonic horizontal motion. The result shows that the amplifications of the in-line force and transverse force acting on a vortex-excited cylinder are large in the range of Keulegan-Carpenter number ( KC) about 5 to 10. It implies that the fluid-structure interaction is large in this range of $\mathrm{KC}$ numver. The differences between the flow pattern around the vortex-excited cylinder in resonance condition and those around the rigidly mounted cylinder are observed in the case of $\mathrm{KC}=8.4$.

Keywords : Vortex-excited vibration, Lift force, In-line force, Non-linear Vibration

\title{
1.はじめに
}

柱状海洋構造物は、波の進行方向に作用する進行波力（In-line force）とその直角方向に作用する揚力 (Transverse force) を受ける。進行波力の卓越周波数 $\mathrm{fw}$ w作用波の周波数と同じであるが、揚力の卓越

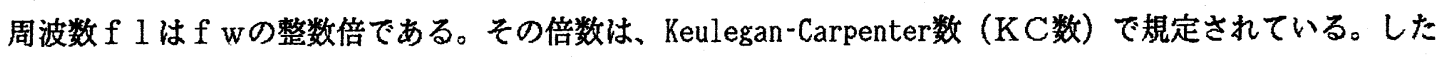
がって、柱状弾性構造物の揚力に対する振動応答特性（渦励振動）は十分に検討される必要がある。

定常一様流中に置かれた構造物の渦励振動問題に関しては、過去多くの研究がなされており、流れと物体 振動との相互作用によるLocking-on現象という工学的にも大変重要な振動応答特性が明かにされている1)。 波動場における柱状弾性構造物（例えば、石油掘削用ライザー管等）の渦励振動問題においてもこの流れと 物体との相互作用効果は考虑される必要がある。しかし、主流速度が時間的に振動し、かつその大きさが水 樑方向に変化する等の複雑な流れ場特性を有する波動場におけるこの相互作用問題はまだ十分に把握されて いないようである2!。

本研究は、波動場における上記相互作用問題を明 かにするための第一段階として、複雑な波動場の流 れ特性を簡単に表現している一様振動流中で渦励振 動しているa)円柱に作用する流体力の評価とb)円柱 からの放出渦挙動の観察を行ない、流れと物体との 相互作用効果をしらべたものである。

\section{2. 実験装置及び方法}

実験は、水平方向に正弦運動する振動台上に固定 された鉄枠製ガラス張り水槽を用いて行つた（振動 流発生装置)。実験装置の概略を図一1に示す。支

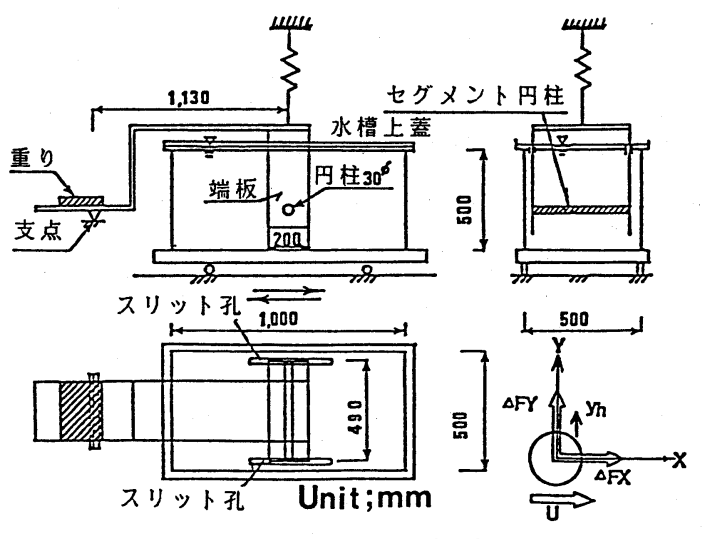

図一 1 実験装置の概略 
点と引つ張りバネを用いて、水槽内に水平設置された試験円柱（外径 $D=3 \mathrm{~cm} 、$ 長さ $=49 \mathrm{~cm} ）$ は、水槽の振動方 向と直角な方向（Y方向、揚力方向）にのみ振動可能である。水槽の振動に伴って生じる自由水表面の動搂 を防ぐために、水槽上面にはアクリル板製の上蓋が設けられている。試験円柱の両端は、この上蓋内に設け られたスリット孔（幅＝8mm）を通る 2 枚の端板で支持されている。試験円柱に作用する流体力の湘定を行 うために、小型 2 分力計に片持梁型式で接続されたセグメント円柱（外径 $=3 \mathrm{~cm}$ 、長さ $=3 \mathrm{~cm}$ ）が試験円柱内に 設けられている。光学式変位計を用いて試験円柱振動変位 $\mathrm{y} h$ 時間変化を測定した。円柱後流渦の挙動観察 をおこなうために、流れの可視化を行った。トレーサにはガラス製粒子（比重 0.98-1.02、平均粒径 $60 \mu$ ) とポリスチレン粒子（此重䄪 1.05、平均粒径 $1 \mathrm{~mm}$ ) を用いた。流況の撮影にはビデオカメラを用いた。

実験に先立ち、滅衰自由振動実験を行い、試験円柱の空中及び静水中における固有振動fna、fnw、と減衰定 数hta、htwをそれぞれ求めた。円柱の鈶值方向に載荷された分銅荷重とバネ伸張量の関倸よりバネ定数を求 めた。このバネ定数と水中固有振動数fnwより、水中付加質量含む試験円柱の換算単位長質量mew及びMass ratio值 (=mew/ $\rho D^{2} 、 \rho:$ 水の密度、D:円柱径) を算定した。

本実験で行つた测定ケースを表- 1 に示す。

CaseA1は、KC数を8.37に固定し振動台の振動周波数（=振

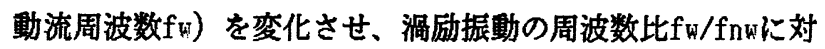
する変化特性を調べたものである。

CaseA2は、共振時における渦励振動のKC数に対する変化特 性を調べたものである。この場合、振動流の周波数fwは水中 固有振動数fnwの1/2に固定されている。CaseR1、CaseR2は、 固定的に設置（固定円柱）された上記試験円柱に作用する流 体力特性をCaseA1、CaseA2と同様な作用振動流のもとでそれ ぞれ調べたものである。上記一連の実験においては、円柱に 作用する流体力計测と円柱後流渦観察の同時測定を行つた。

表 -1 実験条件

\begin{tabular}{|l|ccc|}
\hline \multicolumn{5}{|c|}{ 表 -1} & 実驗条件 \\
\hline & $\mathrm{fnw}(\mathrm{Hz})$ & $\mathrm{fw}(\mathrm{Hz})$ & $\mathrm{KC}$ 数 \\
\hline Case V1 & 0.92 & $0.4-0.6$ & 8.37 \\
Case V2 & 0.92 & 0.46 & $4.2-18.8$ \\
Case R1 & $\mathrm{fnw}>0.92$ & $0.4-0.6$ & 8.37 \\
Case R2 & $\mathrm{fnw}>0.92$ & 0.46 & $4.2-18.8$ \\
\hline 固有振動数 & $\mathrm{fna}=1.08 \mathrm{~Hz} 、 \mathrm{fn} w=0.92 \mathrm{~Hz}$ \\
減衰定数 & $h t a=0.01 \quad$, htw $=0.04$ \\
Mass ratio值 & $\mathrm{mew} / \rho \mathrm{D}^{2}=8.87$ \\
\hline
\end{tabular}

\section{3. 振動方程式}

空中における試験円柱体の減衰自由振動方程式は(1)式で表せる。

$$
\mathrm{mea} \cdot \ddot{\mathrm{y}} \mathrm{h}+\mathrm{Ca} \cdot \dot{\mathrm{y}} \mathrm{h}+\mathrm{K} \cdot \mathrm{yh}=0
$$

式中、y $\mathrm{y}$ は円柱の y 方向振動量である。mea、Caは空中における試験円柱の換算単位長さ当りの質量及び滅 衰保数である。Kは換算バネ保数である。(1)式は通常(2)式のように表現される。

$$
\ddot{\mathrm{y}} \mathrm{h}+2 \zeta \mathrm{ta} \cdot 2 \pi \mathrm{fna} \cdot \dot{\mathrm{y}} \mathrm{h}+(2 \pi \mathrm{fna})^{2} \cdot \mathrm{y} \mathrm{h}=0
$$

式中、fna, $\zeta$ taは次式で示される円柱体の空中における固有振動数及び減衰定数である。

$$
\begin{aligned}
& \text { fna }=(\mathrm{K} / \mathrm{mea})^{1 / 2} / 2 \pi \\
& \zeta \text { ta }=\mathrm{Ca} /(2 \cdot 2 \pi \text { fna } \cdot \text { mea })
\end{aligned}
$$

静水中における円柱体の減衰自由振動方程式は(5)式で示される。

$$
\mathrm{mea} \cdot \ddot{\mathrm{y}} \mathrm{h}+\mathrm{Ca} \cdot \dot{\mathrm{y} h}+\mathrm{K} \cdot \mathrm{yh}=-\left(\mathrm{Cm} \cdot \rho \cdot \pi \mathrm{D}^{2} / 4 \cdot \ddot{\mathrm{y}} \mathrm{h}+\mathrm{Cd} \cdot \rho / 2 \cdot \mathrm{D} \cdot|\dot{\mathrm{y}} \mathrm{h}| \cdot \dot{\mathrm{y} h}\right)
$$

右辺は、静水中で振動する円柱に作用する流体力をモリソン公式を用いて表したものである。その第 1 項は、 円柱の振動加速度 $\ddot{\mathrm{y}} \mathrm{h}$ に比例する慣性力項である。第 2 項は、円柱の振動速度 $\mathrm{y}$ hの2乗に比例する抗力項であ る。式中Cd、Cmは、慣性力你数及び抗力倸数である。(5)式を、次式のように变形する。

$$
\left(\mathrm{mea}+\mathrm{Cm} \cdot \rho \cdot \pi \mathrm{D}^{2} / 4\right) \cdot \ddot{\mathrm{y}} \mathrm{h}+(\mathrm{Ca}+\mathrm{Cd} \cdot \rho / 2 \cdot \mathrm{D} \cdot|\dot{\mathrm{y} h}|) \cdot \dot{\mathrm{y} h}+\mathrm{K} \cdot \mathrm{yh}=0
$$

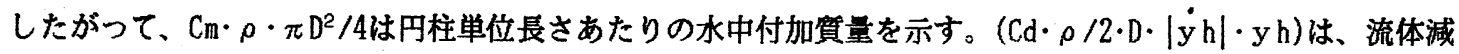
衰力を示す。(6)式は、通常(7)式のように表現される。

$$
\ddot{y} h+2 \zeta t \omega \cdot 2 \pi f n \omega \cdot \dot{y} h+(2 \pi f n \omega)^{2} \cdot y h=0
$$


式中、 $\mathrm{fnw} ， \zeta$ twは、次式で示される円柱体の静水中における固有振動数及び減衰定数である。

$$
\begin{aligned}
& \mathrm{fna}=(\mathrm{K} / \mathrm{mew})^{1 / 2} / 2 \pi \\
& \zeta \mathrm{ta}=(\mathrm{Ca}+\mathrm{Cd} \cdot \rho / 2 \cdot \mathrm{D} \cdot \mid \dot{\mathrm{y}} \mathrm{h} \mathrm{V} /(2 \cdot 2 \pi \mathrm{fnw} \cdot \mathrm{mew})
\end{aligned}
$$

ここで、mewは水中における試験円柱の換算単位長質量であり次式で示される。

$$
\text { mew }=\mathrm{mea}+\mathrm{Cm} \cdot \rho \cdot \pi \mathrm{D}^{2} / 4
$$

この振動系に、振動的な外力（＝y 方向流体力： $\Delta \mathrm{FY})$ が作用する場合の振動方程式は次式となる

$$
\ddot{\mathrm{y}} \mathrm{h}+2 \zeta \mathrm{tw} \cdot 2 \pi \mathrm{fnw} \cdot \dot{\mathrm{y}} \mathrm{h}+(2 \pi \mathrm{fnw})^{2} \cdot \mathrm{y} h=\Delta \mathrm{FY} / \mathrm{mew}
$$

$\Delta \mathrm{FYの}$ 第一近似值としては、同じ流れ中に固定的に設置された同円柱（固定円柱）に作用する流体力 $\Delta \mathrm{FYR}$ 用いられる。しかし、渦励振動時には、流れと円柱との相互作用により $\Delta$ FYRより変化するものと考えられる。

\section{4.実験結果および考察}

空中および氷中における円柱体の減衰自由振動記録例を図-2 のa),b)にそれぞれ示す。これら記録例より,滅衰変化する円柱 振動の半振幅值 $Y h$ に対する減衰定数を対数隇衰法を用いて算定 した。空中における隇衰定数

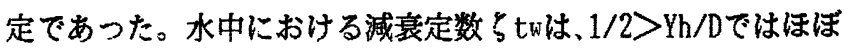
一定であつたが、1/2<Yh/DではYh/Dの増加に伴い増加した。こ れは、Yh/Dの增加に伴い生しる円柱後流渦による圧力抵抗によ るものと思われる。表一1に示した ら ta及び おける代表値である。

図中には、同時に計測されたセグメント円柱に作用するカ $\Delta$ $\mathrm{FX} 、 \Delta \mathrm{FY}$ の記録例をも示している。 $\Delta \mathrm{FX} 、 \Delta \mathrm{FY}$ の時間変化はYh/ Dと同期している。空中における $\Delta \mathrm{FY}$ の值は、円柱の振動に伴い

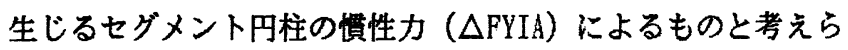
れる。水中における $\Delta \mathrm{FY}$ 值は、上記慣性力 $(\triangle \mathrm{FYIA})$ に水中 付加慣性力 $(\triangle \mathrm{FYIW})$ 加加わったものと考元ら机る。若千被め られる $\Delta \mathrm{FX}$ の值は、有限半径（図-1参照）を有する円弧を描い て円柱が振動する結果、二分力計の力計測方向が水平方向より ずれるために生じるものと考元られる。空中、水中におけるこ

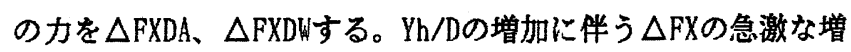
加は、前述の円柱後流渦の出現によるものと思われる。

図-3は、CaseV1の実験で得られた無次元応答振動量 $\mathrm{Yh} / \mathrm{D}$ 周波
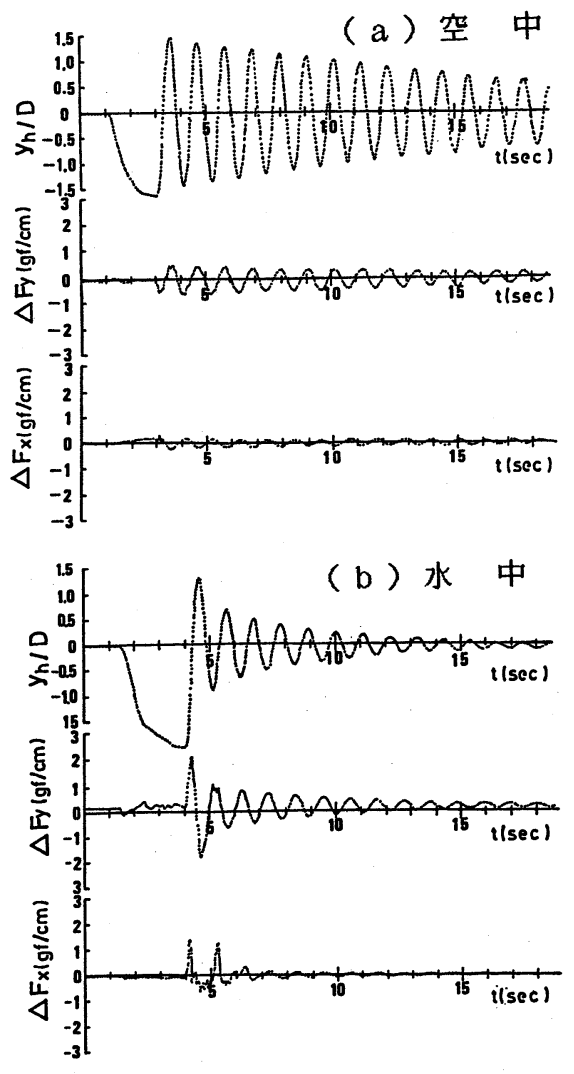

図-2 減衰自由振動記録例 比 $\mathrm{fw} / \mathrm{fnw}$ の関係を示す。 $\mathrm{KC}=8.37$ の場合、固定円柱に作用する $\Delta$

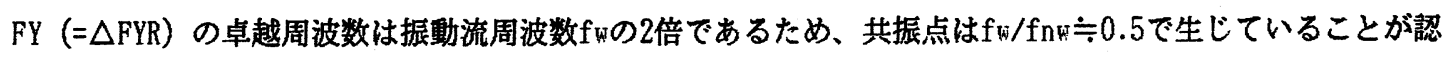

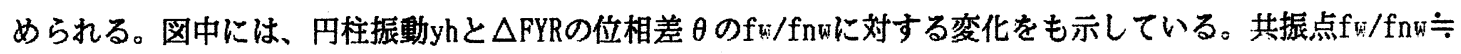
0.5 では、線形强制振動方程式による理論值（ $\theta=90^{\circ} ）$ とほほ一致している。

図-4は、 KC=6.28,8.37並びに16.78の場合における、セグメント円柱に作用する力と水槽の水平移動量 aの 時間変化例をそれぞれ示したものである。これら図中、a)は固定円柱に作用するX,Y方向の流体力 $\Delta \mathrm{FXR、 \Delta}$ FYRの時間変化例を示す。b)は、共振状態で瀜嚈振動しているセグメント円柱に作用するX、Y方向の検出力か

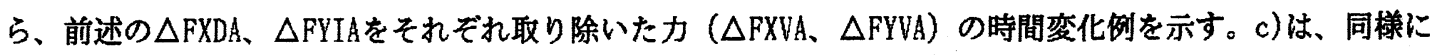

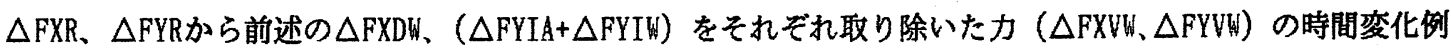
を示す。 $\triangle \mathrm{FXVA、} \triangle \mathrm{FYVA}$ 、振動円柱の単位長当りに作用する正味のX,Y方向流体力と考元られる。 $\triangle \mathrm{FYVWは}$ 

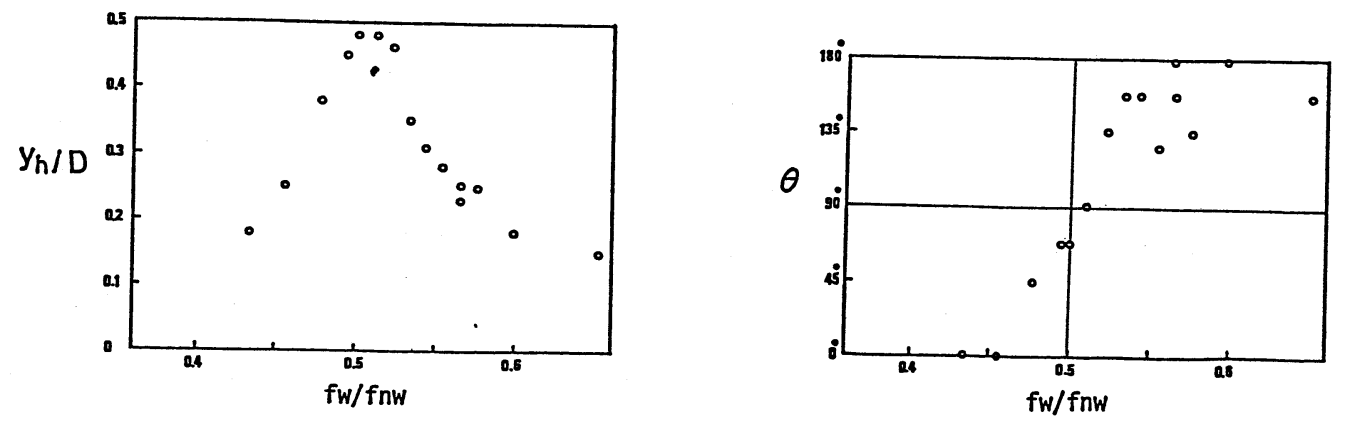

図ー3 Yh/D、 $\theta$ とfw/fnwの関倸

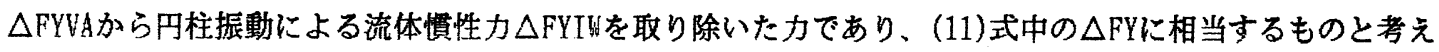

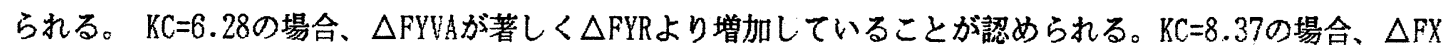

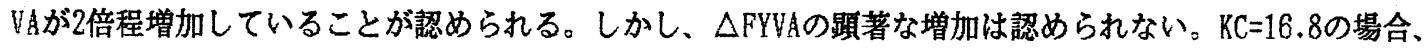
$\triangle F X V A 、 \triangle F Y V 、 \triangle F X W W 、 \triangle F Y W$ の增加現象は認められず、多少減少している場合も認められる。

固定円柱と振動円柱に作用する流体力の変化特性をより詳しく調べるために、作用流体力のフーリエ解析 を行い、次式で定義される流体力倸数を求めた。

$$
\begin{aligned}
& \mathrm{CXR}(\mathrm{N})=\triangle \mathrm{FXR} \text { の振動流周波数 } \mathrm{f} w \text { のN倍周波数成分／( }\left(\rho / 2 \cdot \mathrm{D} \cdot \mathrm{Um}^{2}\right) \\
& \text { CYR }(\mathrm{N})=\triangle \mathrm{FYR} \text { の振動流周波数 } \mathrm{fw} \text { 倍周波数成分 } /\left(\rho / 2 \cdot \mathrm{D} \cdot \mathrm{Um}^{2}\right) \\
& \mathrm{CXVA}(\mathrm{N})=\triangle \mathrm{FXVA} \text { の振動流周波数 } \mathrm{f} w \text { のN倍周波数成分／( }\left(\rho / 2 \cdot \mathrm{D} \cdot \mathrm{Um}^{2}\right) \\
& \mathrm{CYVA}(\mathrm{N})=\triangle \mathrm{FYVA} \text { の振動流周波数 } \mathrm{f} \omega \mathrm{W} \text { 倍周波数成分 } /\left(\rho / 2 \cdot \mathrm{D} \cdot \mathrm{Um}^{2}\right) \\
& \mathrm{CXVW}(\mathrm{N})=\triangle \mathrm{FXVW} \text { の振動流周波数 } \mathrm{f} \text { wのN倍周波数成分 } /\left(\rho / 2 \cdot \mathrm{D} \cdot \mathrm{Um}^{2}\right) \\
& \mathrm{CYWW}(\mathrm{N})=\triangle \mathrm{FYWW} \text { 振動流周波数 } \mathrm{fw} \text { のN倍周波数成分 } /\left(\rho / 2 \cdot \mathrm{D} \cdot \mathrm{Un}^{2}\right)
\end{aligned}
$$

これら各保数とKC数との関係を図-5に示す。図中b)、C)には、固定円柱の卓越周波数成分值CYR (2) 又はCXR (1)を比較のために記入している。CXVA(1)及びCXVW(1)は5<KC<12の範囲でCXR(1)より増加している。CYA(2 )は5<KC<8の範囲でCYR(2)より増加している。CYWW(2)は5<KC<6の範囲でCYR(2)より増加しているが、7<KC<1 5の範囲では減少している。KC数が小さな範囲で振動時の流体力係数の増加が大きくなる理由としては、不十 分な固定円柱からの円柱後流渦の発達が円柱振動と流れとの相互作用により促進されたためと考えられる。

図-6は、KC=8.37の場合における、固定円柱および共振時円柱まわりに生成・発達する円柱後流渦挙動を模 式的にそれぞれ示したものである。固定時の円柱後流渦挙動は、振動流の半周期毎に上下に非対象な渦対が 生成発達されるパターンであり、既往の観測結果（例えば3))とよく類似している。順流時（U<0)には円柱 右下に、逆流時（Uく）には円柱左下にそれぞれ新たな渦対が形成されている。順流時における新たな渦の生 成発達強度は、逆流時に比べて強い。従って、半周期毎に生じる渦対の生成発達過程は、上下に加えて左右 にも若干非対称である。

共振時の円柱後流渦の挙動は、大略的には固定時の場合と同様であり円柱の片㑡（下側）のみに渦対の生 成発達が認められるが、以下の点において固定時の場合と異なつている。

1)渦対の生成発達過程はほほ左右対象である。

2)円柱振動量が上側に最大になる位相近傍で顕著な渦対が円柱の右下、及び左下にそれぞれ形成される。従 つて.固定時と共振時における渦対の生成発達過程の間には位相差が存在する。

3) 周期的に非常に安定した円柱共振振動が存在する結果、共振時における渦対の生成発達過程は、固定時 の場合に比べてより安定である。

4) 静固定時と共振時における渦の生成発達強度の差は明確に認められないが、共振時における渦の幅は固 定時に比べて大きいようである。この現象は、共振時におけるX方向流体力の増加の一因と推测できる。 


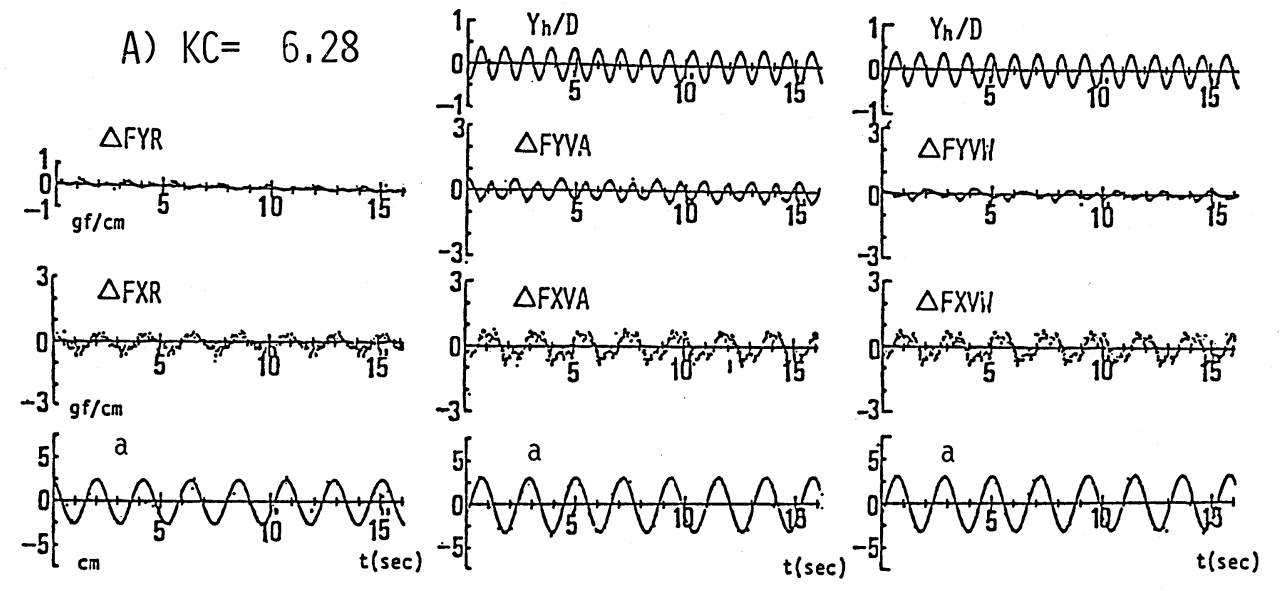

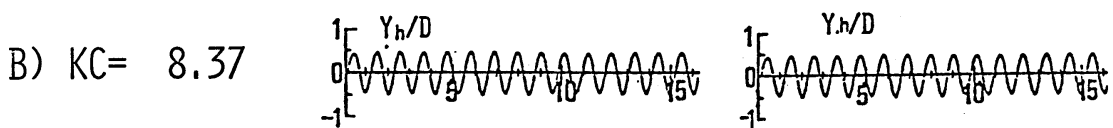

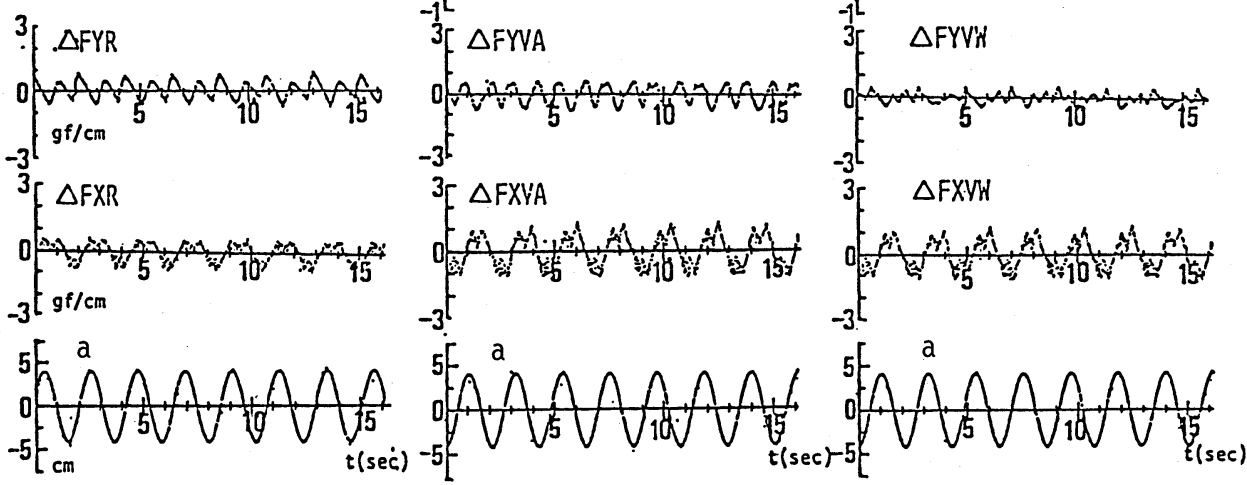

s:

C) $\mathrm{KC}=16.78$.
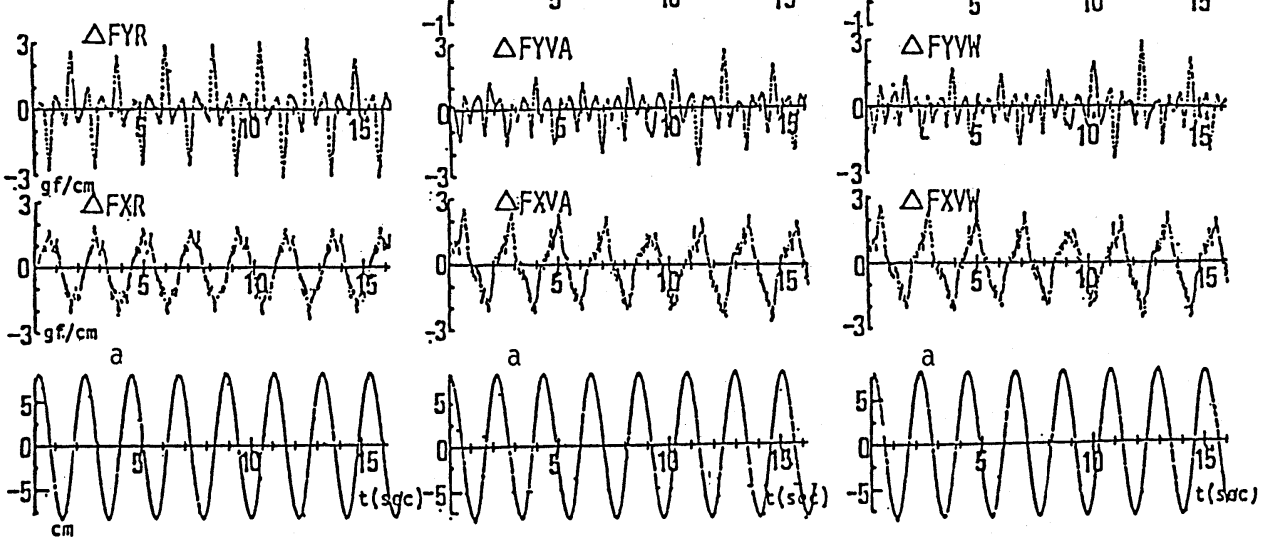

図ー4固定円柱および振動円柱（共振）に作用する流体力 
CXR(N)

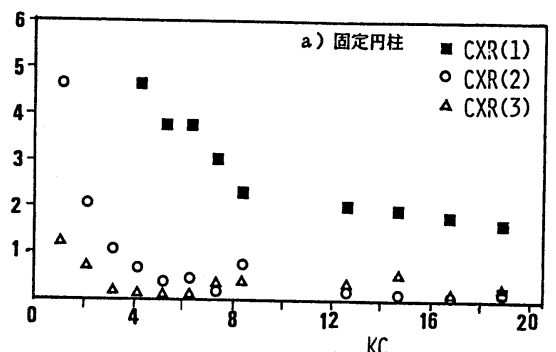

CXVA(N)

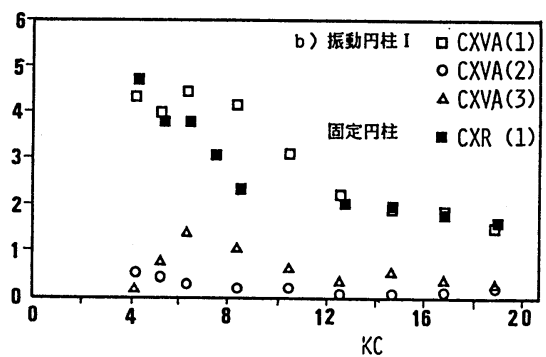

CXVW(N)

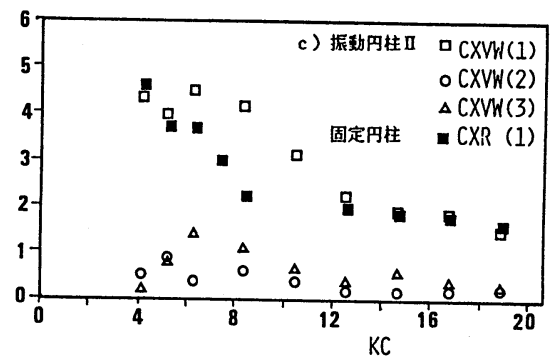

CYR(N)

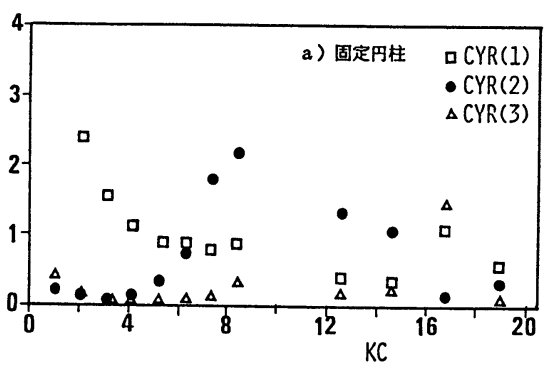

CYVACN)

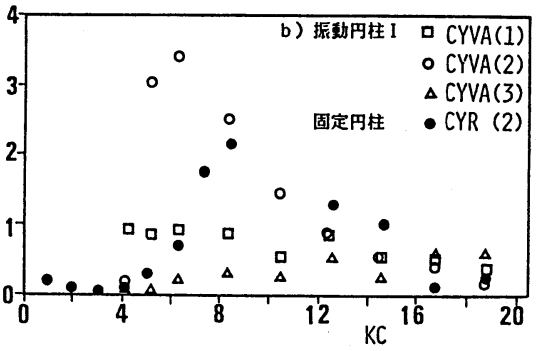

CYWW(N)

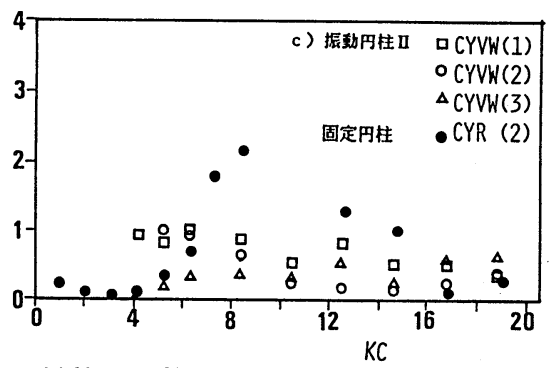

図-5 固定円柱及び振動円柱の流体力係数とKC数との関倸

\section{4.おわりに}

以上は、渦励振動時における円柱振動と流れの相互作用効果を、 作用流体力と円柱後流渦挙動の面から評価することを試みたもので ある。共振現象による作用流体力の増加が起こるKC数の領域は限ら れることが明かとなった。また、円柱振動に伴う後流渦挙動の変化 を定性的に把握した。今後は、静止時及び共振時における作用流体 力と円柱後流渦挙動との定量的評価を渦糸モデル等を用いて試み、 この種の相互作用効果をさらに詳しく检討したい。

\section{参考文献}

1) Blevirs,: Flow-induced vibration, Van Nostrand Reinheld, $363 \mathrm{p} ., 1977$.

2)林、Chaplin：波動場にお汁る直円柱の渦励振動について、

第32回海岸工学論文集、pp.633-637, 1985.

3) Obasaju, et al.: A study of forces, circulation and patterns around a circular cylinder in oscillating flon, J.M.F., 196, pp.467-494, 1988.

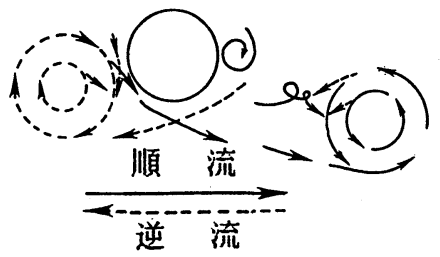

(a) 固定円柱

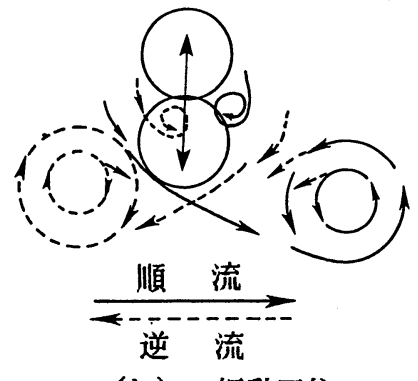

(b) 振動円柱

図一6 円柱後流渦の挙動 